\title{
ANÁLISE DOS INDICADORES SOCIAIS INTERNOS DE RESPONSABILIDADE SOCIAL DAS MÉDIAS E GRANDES EMPRESAS CERTIFICADAS PELA ASSEMBLÉIA LEGISLATIVA DE MATO GROSSO
}

\author{
Cleide Gonçalves Souza ${ }^{1}$ \\ Flávio Amaral Oliveira ${ }^{2}$ \\ Luciênio Rosa e Silva Junior ${ }^{3}$
}

\section{RESUMO}

$\mathrm{O}$ artigo tem como objetivo demonstrar os índices de investimentos sociais internos das médias e grandes empresas certificadas pela Assembléia Legislativa de Mato Grosso (ALMT); comparar entre as médias e grandes empresas certificadas pela ALMT os investimentos sociais internos no ano de 2010; descrever as razões que levam as empresas privadas de Mato Grosso publicarem Balanço Social (BS). A pesquisa deste estudo foi classificada como exploratória. Neste estudo o procedimento adotado foi de coleta de dados documental, extraído do sítio da Assembléia Legislativa de Mato Grosso (ALMT) os Balanços Sociais das médias e grandes empresas (M.G.E.) que possuem o certificado de responsabilidade social. Foram feitos a soma dos investimentos anuais dos indicadores sociais de ambiente interno destas empresas, o quanto as empresas, investiram por ano, em seu ambiente interno. Nos resultados foram identificados que no ano de 2005 as 4 empresas investiram mais de $\mathrm{R} \$ 17$ milhões em indicadores de ambiente interno, um percentual de 2,66\% da Receita Líquida. No ano de 2010, o qual foram 20 empresas, os investimentos foram mais de $\mathrm{R} \$ 144$ milhões, porém caiu o percentual em relação à Receita Líquida para 1,54\%. Foi concluído que durante o período de 2005 a 2010 os Indicadores Sociais Internos que mais recebeu investimento foi da "alimentação" e o que teve menor valor investido foi de "creche ou auxílio creche".

Palavras-chave: Comissão mista; balanço social; ambiente interno; certificado.

\section{INTRODUÇÃO}

Aprender é criar possibilidades para que o indivíduo chegue as fontes do conhecimento que estão à sua disposição na sociedade. Na intenção de analisar os motivos que levam às empresas a investir em Responsabilidade Social, o estudo vem para investigar o quanto as médias e grandes empresas de Mato Grosso investem em Indicadores Sociais de Ambiente Interno. O consumidor procura conhecer a empresa que se preocupa com o meio ambiente, com seus funcionários, com o impacto ambiental que irá causar sua atividade na sociedade. Desta forma o consumidor procura comprar das empresas que são responsáveis

\footnotetext{
1 Acadêmica do curso de Ciências Contábeis da UNEMAT - Campus de Tangará da Serra, e-mail: cleidegoncalvesouza@ hotmail.com

2 Professor do curso de Ciências Contábeis da UNEMAT - Campus de Tangará da Serra, e-mail: flavioamaral@unemat.br

${ }^{3}$ Mestre em Ciências Ambientais pela Universidade do Estado de Mato Grosso. Professor do curso de Ciências Contábeis da UNEMAT - Campus de Tangará da Serra, e-mail: lucieniojunior@ unemat.br 
socialmente. As empresas buscam o marketing como ferramenta de aumento de suas vendas, dessa forma a responsabilidade social acaba sendo umas das fontes de informação que leva o consumidor a escolher esta ou aquela empresa para consumir seus produtos. Com as suas ações sociais e ambientais a empresa poderá conquistar esse público que está bem informado sobre suas atitudes sociais.

O estudo apresenta os investimentos financeiros efetuadas pelas empresas em seu ambiente interno, para conhecimentos acadêmicos e dos contadores. De forma que o público interno, quando trabalha satisfeito e com qualidade de vida, tanto social como no trabalho, o seu rendimento é maior, trazendo assim aumento na qualidade dos produtos e serviços da organização, gerando mais rendimentos a empresa em questão. Apresenta a evolução dos investimentos financeiros no seu público interno durante o período do exercício de 2005 ao exercício de 2010 que foram premiadas com o selo de Responsabilidade Social. Informa o percentual que foi aplicado em cada setor deste indicador. A interação da empresa com a comunidade interna e externa torna necessário apresentar o Balanço Social (BS), pois sendo este um demonstrativo contábil que visa à apresentação de informações sobre a atuação da empresa, apresenta informações qualitativas e quantitativas sobre a posição social da mesma, perante ao público interno, a sociedade e o meio ambiente.

Segundo Siqueira (2005) é notável o crescimento da elaboração e publicação deste demonstrativo, apesar de não ser obrigatório no Brasil. Esse crescimento se deve a mudança no contexto empresarial, vivenciada no século $\mathrm{XX}$, em função da maior exigência dos stakeholders por uma gestão socialmente responsável.

Nogueira (2005) dá exemplos de stakeholders que são os fornecedores, governos, acionistas, empregados, sindicatos, organizações sociais, concorrentes, clientes, e todos que interessem pelo desenvolvimento social e econômico da empresa em questão.

A Contabilidade Social é utilizada para a elaboração do Balanço Social (BS), sendo que esta contabilidade se preocupa com as relações entre a sociedade e a empresa, enquanto a contabilidade nacional está voltada para os resultados gerais da economia.

No Brasil, ainda não existe lei que obrigue a padronização e nem publicação do BS, ao contrário de alguns países como França, Portugal, Alemanha, Holanda, Bélgica, Espanha, Inglaterra. Sendo assim a falta de uma legislação e de padronização do BS permite que muitas empresas sejam omissas na sua divulgação, dando referência somente a informações de interesse próprio. 
Embora não seja obrigatória em lei a publicação do Balanço Social, cada vez mais ele firma-se como um instrumento de gestão das empresas. A cada ano cresce o número de empresas que publicam seus balanços sociais. Várias empresas estão prestando contas de suas ações sociais para seus acionistas e para o público em geral. É sinal de que empresários do país estão assumindo uma nova postura diante do social: a de que devem atuar nesta área, pois não é apenas responsabilidade do governo fazê-lo. (FREIRE, 2001)

Segundo Baggenstoss e Donadone (2009) com a crescente mobilização nacional da sociedade para a utilização das práticas de responsabilidades sociais se tornarem lei, há um projeto lei no senado. Porém o Estado do Mato Grosso do Sul foi o primeiro a criar a lei em âmbito estadual, em 2000. O segundo Estado a criar a lei, foi Mato Grosso, por sugestão de profissionais da contabilidade, assim como no MS. A Lei 7.687 que foi sancionada em 2002 criou o Certificado de Responsabilidade Social, com o intuito de promover o reconhecimento público de organizações que desenvolvem projetos e promovam a qualidade de vida dos seus colaboradores, da comunidade onde está inserida e do meio ambiente. Algumas empresas, mesmo não existindo obrigatoriedade, sentem a necessidade de demonstrar sua preocupação com o social e apresentam suas ações publicando seu BS, sendo que no Mato Grosso publicam conforme a Lei 7.687 de 25/06/2002 e o edital da Comissão Mista de Responsabilidade Social da ALMT.

Há várias vantagens para as empresas que publicam o BS, pois ela evidencia informações de interesse dos diversos stakeholders da organização:

Para os trabalhadores como forma de indicação da situação social em que eles estão inseridos dentro da empresa. Para os gestores, o balanço social é uma ferramenta de gestão de recursos humanos, à medida que fornece para os trabalhadores e para os gestores, indicações dos efeitos das políticas de recursos humanos adotada pelas empresas (MARTINS, 1996, p.6)

O crescimento da exigência da sociedade em responsabilidade social faz com que as empresas invistam em seu ambiente interno, dessa forma a empresa também fortalece sua marca, obtendo reconhecimento pelos seus stakeholders, comprometimento e fidelidade de seus colaboradores. Baseado nisso definiu-se o tema da pesquisa como: Análise dos indicadores sociais internos de responsabilidade social das médias e grandes empresas certificadas pela Assembléia Legislativa de Mato Grosso (ALMT).

Neste contexto de responsabilidade social, juntamente com a premiação dada as empresas privadas chegou-se ao problema deste estudo: qual o investimento das médias e grandes empresas certificada pela ALMT em responsabilidade social no ambiente interno durante o período de 2005 à 2010 ? 
Análise dos indicadores sociais internos de responsabilidade social das médias e grandes empresas certificadas pela Assembleia Legislativa de Mato Grosso

O objetivo geral deste trabalho são os investimentos das médias e grandes empresas certificadas pela ALMT em Responsabilidade Social Empresarial (RSE) através da análise dos Indicadores Sociais - Ambiente Interno, e com objetivos específicos de: a) demonstrar os índices de investimentos sociais internos das médias e grandes empresas certificadas pela ALMT; b) comparar entre as médias e grandes empresas certificadas pela ALMT os investimentos sociais internos no período de 2010; c) descrever as razões que levam as empresas privadas de Mato Grosso publicarem Balanço Social (BS).

Para serem reconhecidas como empresas socialmente responsáveis e receberem o certificado, as médias e grandes empresas de Mato Grosso necessitam se adequarem as normas estabelecidas pelos órgãos competentes. Isso, aliado a crescente valorização da sociedade por responsabilidade social interna leva a hipótese de que: As empresas aumentaram os investimentos em responsabilidade social interna nos períodos de 2005 a 2010.

\title{
2 REFERENCIAL TEÓRICO
}

\subsection{Responsabilidade Social no Brasil}

A responsabilidade social vem sendo destaque nas empresas que valorizam a sua ética, que há muito tempo vem se tratando desse assunto. Com apresentações de BS as entidades promovem o desenvolvimento sustentável interno e externo. Suas relações com os stakeholders, devem contribuir muito para o bem estar social, sendo essas calçadas em valores éticos.

\begin{abstract}
A nova consciência ambiental, surgida no bojo das transformações culturais que ocorreram nas décadas de 60 e 70, ganhou dimensão e situou o meio ambiente como um dos princípios fundamentais do homem moderno. Nos anos 80 , os gastos com proteção ambiental começaram a ser vistos pelas empresas líderes não primordialmente como custos, mas como investimentos no futuro e, paradoxalmente, como vantagem competitiva. (KRAEMER 2004).
\end{abstract}

As entidades devem agir com responsabilidades social com as partes interessadas, que influenciam ou são influenciadas pela sua atuação e são chamados de stakeholders, que são os acionistas, proprietários, investidores, empregados e seus familiares, concorrentes, governos, sindicatos, fornecedores entre outros, ou seja, todo e qualquer elemento físico ou jurídico que interaja com as organizações. 


\title{
2.1.1 Responsabilidade Social Interna
}

Quando a efetivação das práticas de responsabilidade social é voltada para o âmbito interno da empresa, diz-se que a responsabilidade social é interna. Tanabe (2012), afirma que “o objetivo da responsabilidade social interna é promover um ambiente de trabalho saudável, minimizando o impacto dos problemas pessoais sobre o sucesso profissional de cada um". Quando as empresas possuem práticas de responsabilidades que afetam diretamente seus próprios empregados, a saúde, a segurança no trabalho e a gestão dos recursos naturais utilizados na produção própria, significam que há práticas de responsabilidade empresarial interna.

\begin{abstract}
A responsabilidade social interna tem como foco trabalhar o público interno da organização, desenvolver um modelo de gestão participativa e de reconhecimento de seus empregados, promovendo comunicações transparentes, motivando-os para um desempenho ótimo. Este modelo de gestão interna compreende ações dirigidas aos empregados e dependentes, aos funcionários de empresas contratadas, terceirizadas, fornecedoras e parceiras. (COSTA, 2012)
\end{abstract}

São percebidos os efeitos positivos causados pela responsabilidade social no ambiente interno, pois o mesmo refletem na produtividade em virtude do comprometimento da empresa na motivação dos trabalhadores, proporcionando melhores condições e qualidade de vida no trabalho. A empresa que respeita à legislação trabalhista, para surgirem como práticas que propiciem a promoção e o aprendizado permanente, se preocupa e viabiliza o desenvolvimento humano de seus empregados, melhora o nível de informação sobre a empresa, um maior e melhor equilíbrio entre trabalho, família e lazer, possibilitar a igualdade salarial, ampliar as perspectivas profissionais para as mulheres, promove a participação dos lucros para os empregados, permite que empregado atue em algumas decisões da empresa, respeita o trabalho e aproveitamento adequado da formação dos trabalhadores, e a não descrimina, esta garantindo o sucesso de seus colaborados e promovendo a responsabilidade social interna.

\subsection{Contabilidade Social}

Quanto a sua definição não existe divergência acentuadas, entre os autores contemporâneos que tratam da matéria.

É definida como uma técnica, similar às dos sistemas convencionais de contabilidade, que se propõe a apresentar uma síntese de informações, cifradas em unidades monetárias, sobre vários tipos de transações econômicas que se verificam, em determinado período de 
tempo, entre os diversos setores e agentes do sistema econômico de um país. (ROSSETTI, 1988, p. 20)

$\mathrm{Na}$ Contabilidade Social, por meio do Balanço Social (BS), que se fornecem informações importantes sobre a sua retribuição ao meio em que esta inserida. "As demonstrações contábeis representam o principal canal de comunicação entre a sociedade e a empresa que presta contas a comunidade, sobre sua conduta e estado patrimonial" (RIBEIRO, et al 2005).

\subsection{Evidenciação da Interação da Empresa com a Sociedade}

Elaborar e publicar o BS faz das empresas eticamente responsáveis. Dessa forma fornecem informações úteis aos dirigentes para que os mesmos possam tomar decisões, baseadas nestes dados sociais. Esses indicadores propiciam integração entre dirigentes e funcionários, de forma a criar expectativas que chegarão até os patrões de forma sistêmica e quantificada. Informa aos stakeholders como a empresa encara suas responsabilidades quantos ao seu ambiente interno e corpo funcional. Outra vantagem, como conseqüência dos investimentos, é o aumento do lucro e a satisfação dos funcionários e dos consumidores. Também colabora com o Estado na formulação das políticas públicas, para elaboração de leis e normas legais que regulamentem as atividades das empresas.

\subsubsection{Balanço Social}

De acordo com Tinoco (2001), o Balanço Social é instrumento de gestão e informação que tem por objetivo mostrar, da forma mais transparente, informações econômicas e, principalmente sociais, relativas ao desempenho das entidades, para todos os seus usuários, inclusive seus funcionários. É um demonstrativo que as empresas apresentam anualmente, o qual reuniu um conjunto de informações sobre os projetos de ações sociais e benefícios voltados ao seu público interno e externo. Como instrumento de gestão e de informação o Balanço Social, que é muito útil, visa evidenciar de forma mais transparente possível, as informações contábeis, econômicas, ambientais e sociais do desempenho das entidades, aos mais diferenciados interessados da informação, na busca do desenvolvimento sustentável.

O balanço social é um instrumento de demonstração das atividades das empresas, com ênfase no social, que tem por finalidade transmitir maior transparência e visibilidade às informações que interessam não apenas aos sócios e acionistas das companhias mas também a 
Análise dos indicadores sociais internos de responsabilidade social das médias e grandes empresas certificadas pela Assembleia Legislativa de Mato Grosso

um número maior de atores: empregados, fornecedores, parceiros, consumidores e comunidade. (LISBOA NETO, 2003)

Segundo Ashley (2005) o BS surgiu em meado dos anos 50 e 60 e ganhou força quando os assalariados e populações da Europa e EUA, insatisfeitos com os efeitos da guerra no Vietnã e com as situações de diferenças sociais, exigiram que as empresas adotassem nova postura e ética diante da sociedade.

A partir da década de 60 do século XX, os trabalhadores, especialmente na Europa e nos Estados Unidos da América, passaram a fazer exigências às organizações no sentido de obterem informações relativas a seu desempenho econômico e social, ampliando a informação que as organizações forneciam, incorporando as sociais (especialmente aquelas relativas ao emprego), tendo em vista a discussão da responsabilidade social, dando assim origem à implantação do Balanço Social, na França em 1977, que evidenciava basicamente os recursos humanos. (TINOCO, 2001, p27)

Na década de 70 começou as preocupações de como e quando as empresas deveriam apresentar os resultados de suas ações sociais para a sociedade. A França foi o primeiro país do mundo a ter uma lei que obriga as empresas que tenham mais de 300 funcionários a elaborar e publicar o Balanço Social. Seu objetivo principal prende-se a informar ao pessoal o clima social na empresa à evolução do efetivo; em suma, estabelecer as performances da empresa no domínio social. Este balanço, segundo Tinoco (2001), é bastante paternalista, pois exclui os fatos econômicos dos fatos sociais.

Tendo como tema principal, o Balanço Social da Empresa, segundo Kraemer (2004), em 1960 foi constituído, com sede em São Paulo, a Associação dos Dirigentes Cristãos de Empresas (ADCE), foi quem organizou em 1977, o segundo Encontro Nacional de Dirigentes de Empresas e em 1979 passou a organizar congressos anuais com o BS sendo principal assunto de reflexão. $\mathrm{Na}$ década de 80 foram considerados os primeiros documentos brasileiros, no estado da Bahia como sendo um BS.

\subsubsection{Modelo IBASE}

Conforme afirma Kraemer (2004) em 1993 foi lançada uma Campanha Nacional da Ação da Cidadania contra Fome, a Miséria e pela Vida, tendo como autor o sociólogo Herbert de Souza, conhecido como Betinho, que fez com que vários empresários se interessassem pela prática de ações sociais. Logo em 1997, em parceria com a Gazeta Mercantil, e o Instituto Brasileiro de Análises Sociais e Econômicas (IBASE), Betinho, lançou um modelo de BS, 
criou o selo, aumentando ainda mais a interesse das empresas em divulgarem seus resultados. Esse modelo proposto, o IBASE, é o mais utilizado no Brasil.

O modelo IBASE, é semelhante aos formatos dos balanços financeiros. Expondo em forma de planilha, os números de associados, informações sobre a folha de pagamentos, os gasto e encargos sociais de funcionários, a participações nos lucros, as despesas com controle ambiental e os investimentos sociais externos na comunidade e sociedade em geral.

No modelo IBASE, o mais usado, é composto primeiramente pela identificação da razão social ou denominação social da empresa, com dados completos, endereço, CNPJ, ramo de atividade e por 43 indicadores quantitativos e 8 indicadores qualitativos, organizados em 7 categorias, apresentados em colunas de 2 exercícios anuais da empresa.

O Edital da ALMT apresenta o "modelo" parecido como o IBASE, que tem a estrutura a seguir: 1 - Base de Cálculo: Indicadores econômicos são as informações financeiras que são apresentadas em milhares de reais e servirão como base a todos os indicadores da empresa: Receita Líquida (RL); Resultado Operacional (RO); Folha de Pagamento Bruta (FPB). 2 Indicadores Sociais Ambientes Internos: São os investimentos voluntários e obrigatórios da empresa que beneficiam seu ambiente interno como: alimentação (gastos com restaurante, vale-refeição, lanches, cestas básicas e outros relacionados à alimentação dos empregados); saúde (plano de saúde, assistência médica, programas de medicina preventiva, programas de qualidade de vida e outros gastos com saúde, inclusive dos aposentados); segurança e medicina do trabalho; capacitação e desenvolvimento profissional (recursos investidos em treinamentos, cursos, estágios (excluído os salários) e gastos voltados especificamente para capacitação relacionada com a atividade desenvolvida pelos empregados); creches ou auxíliocreche (creche no local ou auxílio-creche aos Empregados); previdência privada (planos especiais de aposentadoria, fundações previdenciárias, complementações de benefícios aos aposentados e seus dependentes); educação e cultura (gastos com ensino regular em todos os níveis, reembolso de educação, bolsas, assinaturas de revistas, gastos com biblioteca (excluído pessoal) e outros gastos com educação, gastos com eventos e manifestações artísticas e culturais (música, teatro, cinema, literatura e outras artes)); participação nos lucros e resultados (participações que não caracterizem complemento de salários); outros (seguros (parcela paga pela empresa), empréstimo (só o custo), gastos com atividades recreativas, transportes, moradia e outros benefícios oferecidos os empregados podem ser aqui enumerados). 3 - Indicadores Sociais Ambientes Externos: São investimentos que a empresa faz para a sociedade a qual está inserida e traz os seguintes indicadores: combate à fome e 
segurança alimentar; saúde e saneamento; cultura; educação; esporte e lazer. 4 - Indicadores Ambientais: São os investimentos realizados pela empresa para amenizar ou compensar seus impactos ambientais e para uma qualidade ambiental melhor, através de inovações tecnológicas e programas internos de educação ambiental. Como: investimentos relacionados aos processos produtivos e operacionais da empresa e projetos sociais ambientais em ações de educação ambiental. 5 - Indicadores do Corpo Funcional: São as apresentações dos colaboradores, assim como idade, cargos ocupados, e outras informações sobre vários aspectos, oriundas do departamento pessoal como: total geral de empregados em $31 / 12$; total de admissões; total de demissões; total de estrangeiros em 31/12; total de empregados portadores de necessidades especiais; total de prestadores de serviços terceirizados em 31/12; total de empregados por sexo: feminino e masculino; total de empregados por faixa etária: menores de 18 anos, de 18 a 45 anos, acima de 45 anos; total de empregados por nível de escolaridade: analfabetos, ensino fundamental, ensino médio, ensino técnico, ensino superior, pós graduação; e total de cargos de chefia, por sexo: feminino e masculino. $\underline{6 \text { - Informações }}$ Sobre o Exercício da Cidadania Empresarial: São os indicadores quantitativos, a relação entre a maior e a menor remuneração da empresa e número total de acidentes de trabalho e indicadores qualitativos, de múltipla escolha, onde são apresentadas algumas das diretrizes e processos desenvolvidos pela empresa relacionados a suas políticas e práticas de responsabilidade social. 7 - Outras Informações: Este espaço está destinado para a empresa prestar informações importantes quanto ao exercício de responsabilidade social e cidadania empresarial. Pode ser informações sobre a não utilização de mão-de-obra infantil, ou de trabalho escravo ou degradante entres outras e seu compromisso com a valorização e o respeito a diversidade.

\subsubsection{Modelo Ethos}

Com o propósito de oferecer as empresas uma ferramenta de gestão foi desenvolvido os indicadores Ethos, para o diagnóstico e planejamento das práticas de responsabilidade social. Uma ferramenta de uso interno, que autoavalia a gestão de responsabilidade social como também o planejamento de estratégias e monitoramento do desempenho geral da empresa. É uma organização sem fins lucrativos. Tem como missão de mobilizar, sensibilizar e ajudar as empresas a gerir seus negócios de forma socialmente responsável. Criado por um grupo de empresários e executivos de empresas privadas em 1998, o instituto Ethos é uma 
Análise dos indicadores sociais internos de responsabilidade social das médias e grandes empresas certificadas pela Assembleia Legislativa de Mato Grosso

referencia internacional no assunto. Desenvolve também projetos em parceria com diversas entidades no mundo todo.

$\mathrm{Na}$ busca de incentivar as empresas a perceberem qual a verdadeira razão na publicação dessas informações o instituto Ethos publica o guia de Elaboração do BS e Relatório de Sustentabilidade. Em sua última publicação em 2007, com o objetivo de apontar os elementos fundamentais na elaboração do BS e Relatório de Sustentabilidade, tendo como referencia as metodologias IBASE e GRI, o modelo sugere um detalhamento maior que o modelo IBASE. Os indicadores foram desenvolvidos com o propósito de oferecer as empresas uma ferramenta de gestão para o diagnóstico e planejamento das práticas de responsabilidade social empresarial, disponíveis desde 1999 e atualizado ao longo dos anos.

\subsubsection{Modelo Global Reporting Initiative (GRI)}

O modelo Global Reporting Initiative (GRI) é de âmbito internacional, sendo considerado o mais completo e abrangente dos modelos. Conta com princípios para definição adequada do conteúdo do relatório e para garantir a qualidade da informação relatada, indicadores de desempenho e protocolos técnicos com metodologias.

A GRI é uma organização não-governamental internacional, com sede em Amsterdã, na Holanda, cuja missão é desenvolver e disseminar globalmente diretrizes para a elaboração de relatórios de sustentabilidade utilizadas voluntariamente por empresas do mundo todo.

Comparando os modelos apresentados são poucas as diferenças, todavia tem em comum a abordagem interna e externa da empresa. Divulga no BS as informações sobre faturamento, lucro, número de empregados, folha de pagamento bruta, despesas com alimentação, saúde, segurança do trabalhador, valores de encargos sociais e tributos, doações a comunidade ou relativo ao meio ambiente entre outras.

\subsection{Certificado de Responsabilidade Social da Assembléia Legislativa de Mato Grosso} (ALMT)

Foi criado em 2002, através da lei 7.687 de 25/06/2002 o Certificado de Responsabilidade Social, seus autores são José Riva, Humberto Bosaípo e Eliene Lima que promove o reconhecimento público das instituições, empresas, órgãos públicos e OSCIPs Organizações Sociais de Interesse Público. 
Análise dos indicadores sociais internos de responsabilidade social das médias e grandes empresas certificadas pela Assembleia Legislativa de Mato Grosso

O Certificado de Responsabilidade Social de Mato Grosso promove o reconhecimento público de organizações que desenvolvem projetos que promovam a qualidade de vida dos seus colaboradores, da comunidade onde ela está inserida e do meio ambiente. (ALMT, 2011).

A ALMT através da Comissão Mista de Responsabilidade Social divulga o Edital do Certificado de Responsabilidade Social a cada ano, estabelecendo as regras a serem cumpridas pela empresas, ONGs e OCIPs e demais entidades que desejam receber o certificado.

A Comissão Mista de Responsabilidade Social de que trata o Art $4^{\circ}$ da lei ${ }^{\circ} 8.477-$ D.O. 15/05/2006, nomeada através do Ato nº 07/07 em 02/04/2007, estabelece o regulamento para a concessão do Certificado de Responsabilidade Social, aplicáveis aos BS no exercício de 20X1, referentes ao ano base de 20X0.

O edital específica os objetivos específicos da premiação que tem o intuito de promover debate público sobre responsabilidade social (RS), estimular a apresentação do balanço social (BS), difundir os conceitos, benefícios e ações de RS, incentivar o reconhecimento de esforços conjuntos, sensibilizar a sociedade a adotar postura cidadã, construir e manter relacionamento com empresas e demais entidades que desenvolvam ações ligadas ao tema, disseminar tecnologias sociais com outras empresas e identificar formas inovadoras e eficazes da atuar em parceria com as comunidades na construção do bem-estar comum.

O Balanço Social (BS) documento no qual as empresas apresentam dados que permitam identificar o perfil da atuação social, na disseminação do conhecimento, na melhoria do meio ambiente, proteção da sociedade, sem deixar de lembrar as ações que procuram melhorar a qualidade de vida e do ambiente de trabalho para seus funcionários e seus familiares, juntamente com o Relatório Social, deverá ser entregue até dia de 30 de junho de cada ano, para que as empresas e entidades possam concorrer à premiação. Com estes documentos as empresas e entidades apresentam os dados que permitem identificar o perfil da sua atuação social durante o ano anterior.

A Comissão Mista de Responsabilidade Social é composta por 10 entidades, formada por membros da: Assembléia Legislativa (ALMT), Associação Matogrossense dos Municípios (AMM), Associação de Mulheres de Negócios e Profissionais de Cuiabá (BPW), Conselho Regional de Administração de Mato Grosso (CRA/MT), Conselho Regional de Serviço Social (CRESS 20ª Região - MT), Federação da Agricultura e Pecuária do Estado de Mato Grosso (Famato), Federação das Indústrias de Mato Grosso (Fiemt), Federação do Comércio de Mato 
Grosso (Fecomércio), Serviço Social da Indústria (SESI), Sindicato dos Profissionais de Contabilidade em Mato Grosso (SINCON).

Caberá a esta equipe o trabalho de organizar, coordenar, planejar e deliberar todo o processo da certificação. Assim como receber os BS's dos participantes e analisarem se estão com informações claras e verdadeiras para receberem o certificado. Pois a comissão poderá confrontar essas informações com uma visita à empresa e demais entidades inscritas para ser concedido o certificado, podendo ser até desclassificada se caso haja informações falsas ou não condizentes com a realidade.

As inscrições para o certificado são até o dia 30 de junho de cada ano. As empresas e demais entidades deverão preencher e entregar seu BS e um Relatório Social, conforme sua natureza jurídica, seguindo um modelo específico no edital. Sendo para empresas privadas e terceiro setor: modelo 1 - microempresas e empresas de pequeno porte; modelo 2 - empresas de médio e grande porte; (para pessoas jurídicas cuja receita bruta anual seja superior a R\$ 2.400.000,00); modelo 3 - organizações do terceiro setor; modelo 4 - instituições de ensino e fundações privadas; para órgãos públicos: modelo 5 - prefeituras, secretarias estaduais, autarquias e fundações públicas; modelo 6 - empresas públicas e sociedades de economia mista.

A certificação será dada as empresas e demais entidades aprovadas pela comissão, e os profissionais da contabilidade responsáveis pela elaboração do BS receberão da ALMT uma moção de aplausos pelos trabalhos relevantes de RSE.

Os critérios para aprovação estão descritos no edital e são apresentados em uma declaração emitida pelo responsável legal das empresas e demais entidades afirmando sua responsabilidade social. O edital e os modelos a serem preenchidos estão disponíveis no sitio da ALMT.

A ALMT criou através do Ato $n^{\circ}$ 07/07, em 02 de abril de 2007, que trata o Artigo $4^{\circ}$ da Lei $n^{\circ}$. 8.477 - D.O. 15.05.2006 a Comissão Mista de Responsabilidade Social, para o desenvolvimento desse trabalho.

Conforme texto abaixo:

“Art. $1^{\circ}$ Fica instituído o Certificado de Responsabilidade Social - MT a ser conferido, anualmente pela Assembléia Legislativa do Estado de Mato Grosso, às empresas, órgãos públicos e demais entidades com sede no Mato Grosso que apresentarem seu Balanço Social do exercício anterior”. (MATO GROSSO, LEI N 7.687) 
A ALMT promove um seminário anualmente, para divulgar o Certificado e determinar a data limite de entrega dos BS, assim como apresentar as empresas ganhadoras deste certificado.

O interesse das empresas aumenta a cada ano, desde que o Certificado de Responsabilidade Social foi instituído em Mato Grosso, a $1^{\text {a }}$ edição realizada em 2006 apresentaram o BS do exercício anterior, para receberem o Certificado de Responsabilidade Social 5 empresas, em 2007 foram 19, em 2008 foram 24, em 2009 foram 33, em 2010 passaram para 38 empresas e 2011 foram 42.

\section{METODOLOGIA}

Quanto ao objetivo da pesquisa ela pode ser classificada como exploratória, descritiva e explicativa. A pesquisa deste estudo foi classificada como exploratória, que trata de estudos preliminares sobre um objeto de pesquisa, com objetivo de construir um conhecimento geral sobre o mesmo, que requer um contato prévio com o objeto de pesquisa. É uma sondagem sobre o tema com informações preliminares, com pesquisa bibliográfica e documental via sítio da ALMT sobre às médias e grandes empresas que desde 2006 foram reconhecidas com o selo de responsabilidade.

A caracterização do estudo como pesquisa exploratória normalmente ocorre quando:

Há pouco conhecimento sobre a temática a ser abordada. Por meio do estudo exploratório busca-se conhecer com maior profundidade o assunto, de modo a tornálo mais claro ou construir questões importantes para a condução da pesquisa. (BEUREN, 2003, Apud RIBEIRO, et al 2005)

Pode se definir pesquisa bibliográfica como:

A pesquisa bibliográfica é desenvolvida com base em material já elaborado, constituído principalmente de livros e artigos científicos. Embora em quase todos os estudos seja exigido algum tipo de trabalho dessa natureza, há pesquisas desenvolvidas exclusivamente a partir de fontes bibliográficas. Boa parte dos estudos exploratórios pode ser definida como pesquisas bibliográficas. (GIL, 2008).

Quanto à abordagem dos problemas pode existir a pesquisa com enfoque quantitativo e qualitativo, são casos diferentes de abordar os problemas, que será tratado neste estudo. $\mathrm{O}$ quantitativo o próprio nome já diz, vêm de quantidade, números, valores. Na metodologia trata-se de para Beuren (2003) um emprego de instrumentos estatísticos, tanto na coleta quanto na tabulação dos dados. As técnicas vão desde as mais simples até as mais complexas, 
ex: percentual, média, desvio padrão, análise de regressão entre outras. Tem a garantia de dar resultados precisos, evitando distorções de análise e interpretações.

A pesquisa com abordagem qualitativa, expressa a complexidade de determinado problema, para a compreensão e interpretação do autor da pesquisa. Nessa abordagem, diferentemente da quantitativa, não tem cálculos estatísticos, pois a pesquisa não tem como ser mensurado. Na pesquisa qualitativa concebem-se análises mais profundas em relação ao fenômeno que está sendo estudado. Esta abordagem vai destacar características não observadas por meio de estudo quantitativo. (RIBEIRO, et al 2005).

Para Gil (2008), as técnicas de pesquisas quanto aos procedimentos podem ser classificadas em dois grandes grupos: fontes de "papel” onde está as pesquisas bibliográficas e documental e fornecidos por pessoas está o levantamento ou survey, ex-post-facto, estudo de caso, participante e outras.

Neste estudo o procedimento adotado foi de coleta de dados documental, extraído do sítio da ALMT os BS das médias e grandes empresas que possuem o certificado do selo de responsabilidade social. Foram feitos a soma dos investimentos anuais dos indicadores sociais de ambiente interno destas empresas, o quanto as empresas, investiram por ano, em seu ambiente interno, como saúde, segurança e medicina do trabalho, capacitação e desenvolvimento profissional, creches ou auxílio-creche, previdência, educação e cultura, participação nos lucros e resultados e outros, por critério de percentual proporcional as receitas, como está descrito no modelo IBASE.

Segundo Ribeiro, et al (2005) a técnica da pesquisa documental fundamenta-se no levantamento de documentos, escritos ou não, de primeira mão, ou seja, ainda não foi manipulado ou utilizado para embasamento de uma outra pesquisa. A pesquisa bibliográfica são informações públicas. Com finalidade de colocar o pesquisador em contato direto com a informação escrita sobre o assunto. O levantamento consiste em pesquisar diretamente as pessoas ou entidades em questão. Muitas vezes não se consegue entrevistar ou questionar a todos, assim pode ser feita por amostragem, que é um procedimento estatístico, considerando uma margem de erros.

O levantamento ou survey segundo Gil (2008), as pesquisas de levantamento:

Caracterizam pela interrogação direta das pessoas cujo comportamento se deseja conhecer. Basicamente, procede-se a solicitação e informações a um grupo significativo de pessoas acerca do problema estudado para em seguida, mediante análise quantitativa, obter as conclusões correspondentes dos dados coletados. 
Análise dos indicadores sociais internos de responsabilidade social das médias e grandes empresas certificadas pela Assembleia Legislativa de Mato Grosso

Foram selecionadas as empresas que possuem o certificado de Responsabilidade Social cedido pela ALMT que se enquadram no modelo 2 - empresas de médio e grande porte, que são pessoas jurídicas cuja receita bruta anual seja superior a $\mathrm{R} \$ 2.400 .000,00$, conforme o edital anual.

Com o BS de cada empresa será analisada a média anual da receita líquida e folha de pagamento bruto e suas proporções aplicadas em cada área do ambiente interno, sendo que não há uma freqüência de apresentação do BS dessas referidas empresas todos os anos. Com a somatória e os percentuais dos respectivos setores será feita a análise vertical e horizontal da evolução anual, verificando o crescimento dos investimentos totais das empresas de médio e grande porte, certificadas pela ALMT.

Segundo Matarazzo, “Análise Vertical baseia-se em valores percentuais das demonstrações financeiras. Para isso se calcula o percentual da cada conta em relação a um valor-base. Por exemplo, na Análise Vertical do Balanço calcula-se o percentual de cada conta em relação ao total do Ativo. Análise Horizontal, baseia-se na evolução de cada conta de uma série de demonstrações financeiras em relação à demonstração anterior e/ou em relação a uma demonstração financeira básica, geralmente a mais antiga da série.”

\section{RESULTADOS}

O interesse das empresas em terem um reconhecimento social aumenta a cada ano. Desde que o Certificado de Responsabilidade Social foi instituído em Mato Grosso, a $1^{\text {a }}$ edição realizada em 2006 teve 5 empresas, em 2007 foram 18, em 2008 foram 24, em 2009 foram 33, em 2010 passaram para 38 empresas e 2011 foram 42 que apresentaram o BS para receberem o Certificado de Responsabilidade Social. Estão distribuídas nos municípios de: Barra dos Bugres, Cáceres, Cuiabá, Dom Aquino, Juara, Lucas do Rio Verde, Nova Olímpia, Rondonópolis, Tangará da Serra, e Várzea Grande. Neste período foram analisados 161 BS, sendo que em 2006, 2008 e 2009 não houve nenhum BS desclassificado, já em outros anos existiram desclassificações conforme mostra o quadro 1.

Quadro 1: Histórico do Certificado de Responsabilidade por ano

\begin{tabular}{|c|c|c|}
\hline ANO & QUANTIDADE CERTIFICADA & DESCLASSIFICADA \\
\hline 2006 & 5 & 0 \\
\hline 2007 & 18 & 1 \\
\hline 2008 & 24 & 0 \\
\hline 2009 & 33 & 0 \\
\hline
\end{tabular}


Análise dos indicadores sociais internos de responsabilidade social das médias e grandes empresas certificadas pela Assembleia Legislativa de Mato Grosso

\begin{tabular}{|c|c|c|}
2010 & 37 & 1 \\
\hline 2011 & 39 & 3 \\
\hline TOTAL & $\mathbf{1 5 6}$ & $\mathbf{5}$ \\
\hline
\end{tabular}

FONTE: ALMT, 2011

Esses certificados foram distribuídos para empresas de apenas 10 municípios, sendo a primeira colocada Cuiabá com 60,90\% e segunda está a cidade de Tangará da Serra conforme o quadro 2.

Quadro 2: Municípios que estão instaladas as empresas com certificado de Responsabilidade Social concedido pela ALMT.

\begin{tabular}{|c|c|c|c|c|c|c|c|c|c|}
\hline & MUNICÍPIO & 2006 & 2007 & 2008 & 2009 & 2010 & 2011 & $\begin{array}{l}\text { QUANTIDADE } \\
\text { CERTIFICADO }\end{array}$ & $\%$ \\
\hline 1 & Barra do Bugres & & & & 1 & 1 & 1 & 3 & 1,92 \\
\hline 2 & Cáceres & & 1 & 1 & 1 & 1 & 1 & 5 & 3,21 \\
\hline 3 & Cuiabá & 2 & 11 & 17 & 19 & 22 & 24 & 95 & 60,90 \\
\hline 4 & Dom Aquino & & & & & 1 & 1 & 2 & 1,28 \\
\hline 5 & Juara & & & & 1 & & & 1 & 0,64 \\
\hline 6 & Lucas do Rio Verde & & & & 1 & 1 & 1 & 3 & 1,92 \\
\hline 7 & Nova Olímpia & 1 & 1 & 1 & 1 & 1 & 1 & 6 & 3,85 \\
\hline 8 & Rondonópolis & & 1 & 1 & 1 & 2 & 2 & 7 & 4,49 \\
\hline 9 & Tangará da Serra & 1 & 2 & 2 & 2 & 6 & 6 & 19 & 12,18 \\
\hline 10 & Várzea Grande & 1 & 2 & 2 & 6 & 2 & 2 & 15 & 9,62 \\
\hline & TOTAL & 5 & 18 & 24 & 33 & 37 & 39 & 156 & 100 \\
\hline
\end{tabular}

Fonte: ALMT, 2011

Durante o período de 2006 a 2011 foram concedidos 156 certificados a 52 empresas, que apresentaram o BS do exercício anterior até o prazo estipulado no edital da ALMT e foram aprovados. Destes certificados 26 são para médias e grandes empresas (M.G.E.) que totalizam 83 certificados, conforme o quadro 3.

Quadro 3: demonstrativo das médias e grandes empresas que tem Certificado de Responsabilidade Social em Mato Grosso, por ano.

\begin{tabular}{|l|r|r|r|c|c|c|c|}
\hline DENOMINAÇÃO SOCIAL & 200 \\
6 & 2007 & $\begin{array}{r}200 \\
8\end{array}$ & $\begin{array}{r}200 \\
9\end{array}$ & 2010 & $\begin{array}{c}\text { 2011 } \\
\text { CERTIFICADO }\end{array}$ \\
\hline EMPRESAS QUE RECEBERAM OS CERTIFICADOS & 4 & 9 & 12 & 18 & 20 & 20 & 83 \\
\hline Açofer Industria Comércio Ltda & & $\mathrm{X}$ & $\mathrm{X}$ & $\mathrm{X}$ & $\mathrm{X}$ & $\mathrm{X}$ & 5 \\
\hline Agro Amazônia Produtos Agropecuários Ltda & & & $\mathrm{X}$ & $\mathrm{X}$ & $\mathrm{X}$ & $\mathrm{X}$ & 4 \\
\hline Agro Amazônia Sistemas Mecanizados Ltda & & & & $\mathrm{X}$ & $\mathrm{X}$ & $\mathrm{X}$ & 3 \\
\hline Bimetal & & & $\mathrm{X}$ & $\mathrm{X}$ & $\mathrm{X}$ & $\mathrm{X}$ & 4 \\
\hline Brasil Telecom S/A - Filial Mato Grosso & & $\mathrm{X}$ & $\mathrm{X}$ & & & & 2 \\
\hline Cemat Rede Energia - Centrais Elétricas Matogros S.A. & & & $\mathrm{X}$ & $\mathrm{X}$ & $\mathrm{X}$ & $\mathrm{X}$ & 4 \\
\hline Data Med Ltda - Medicina Diagnóstica Doyon & & & & & $\mathrm{X}$ & $\mathrm{X}$ & 2 \\
\hline DCP Máquinas e Veículos Ltda & & & & $\mathrm{X}$ & & & 1 \\
\hline
\end{tabular}

Volume 2, Número 3

Revista UNEMAT de Contabilidade

Jan./Jun. 2013

ISSN: 2316-8072 
Análise dos indicadores sociais internos de responsabilidade social das médias e grandes empresas certificadas pela Assembleia Legislativa de Mato Grosso

Cleide Gonçalves Souza, Flávio Amaral Oliveira,Luciênio Rosa e Silva Junior

\begin{tabular}{|l|c|c|c|c|c|c|c|} 
Fiagril Participações S/A & & & & $\mathrm{X}$ & $\mathrm{X}$ & $\mathrm{X}$ & 3 \\
\hline Grupo André Maggi & & $\mathrm{X}$ & $\mathrm{X}$ & $\mathrm{X}$ & $\mathrm{X}$ & $\mathrm{X}$ & 5 \\
\hline Grupo Cometa - Motos Mato Grosso Ltda & & $\mathrm{X}$ & $\mathrm{X}$ & $\mathrm{X}$ & $\mathrm{X}$ & $\mathrm{X}$ & 5 \\
\hline Guavirá Indústria e Agroflorestal Ltda & & & & & $\mathrm{X}$ & & 1 \\
\hline H. Print - Reprografia e Automação de Escritórios Ltda & & & & & & $\mathrm{X}$ & 1 \\
\hline Hospital Santa Rosa - Hosp de Medic Especializada Ltda & & & & & $\mathrm{X}$ & $\mathrm{X}$ & 2 \\
\hline Inasb - Saúde Bucal - Operad de Planos Odontológ Inasb & & & & & $\mathrm{X}$ & $\mathrm{X}$ & 2 \\
\hline Maxvinil Tintas e Vernizes S.A. & & & & & & $\mathrm{X}$ & 1 \\
\hline Refrigerantes Marajá S/A & $\mathrm{X}$ & $\mathrm{X}$ & $\mathrm{X}$ & $\mathrm{X}$ & $\mathrm{X}$ & $\mathrm{X}$ & 6 \\
\hline Renosa Ind Bras de Bebidas Ltda & & & & $\mathrm{X}$ & & & 1 \\
\hline Supermercado Modelo Ltda & & $\mathrm{X}$ & $\mathrm{X}$ & $\mathrm{X}$ & $\mathrm{X}$ & $\mathrm{X}$ & 5 \\
\hline Tractor Parts Distribuidora de Auto Peças Ltda & & & & $\mathrm{X}$ & & & 1 \\
\hline Unimed Cuiabá Cooperativa de Trabalho Médico & $\mathrm{X}$ & $\mathrm{X}$ & $\mathrm{X}$ & $\mathrm{X}$ & $\mathrm{X}$ & $\mathrm{X}$ & 6 \\
\hline Unimed Rondonópolis Cooperativa de Trabalho Médico & & & & & $\mathrm{X}$ & $\mathrm{X}$ & 2 \\
\hline Unimed Vale do Sepotuba - Coop de Trabalho Médico & $\mathrm{X}$ & $\mathrm{X}$ & $\mathrm{X}$ & $\mathrm{X}$ & $\mathrm{X}$ & $\mathrm{X}$ & 6 \\
\hline Usinas Barralcool S/A & & & & $\mathrm{X}$ & $\mathrm{X}$ & $\mathrm{X}$ & 3 \\
\hline Usinas Itamarati S/A & $\mathrm{X}$ & $\mathrm{X}$ & $\mathrm{X}$ & $\mathrm{X}$ & $\mathrm{X}$ & $\mathrm{X}$ & 6 \\
\hline Vitória Régia Água Mineral Ltda & & & & $\mathrm{X}$ & $\mathrm{X}$ & $\mathrm{X}$ & 3 \\
\hline
\end{tabular}

Fonte: Dados da pesquisa, 2012

As empresas de médio e grande porte que receberam o certificado no primeiro ano de lançamento continuaram a apresentar seu BS e receber o Certificado de Responsabilidade Social durante as seis edições deste evento realizado pela ALMT.

O valor em reais investido aumentou do ano de 2005 a 2010 consideravelmente devido ao aumento das empresas, que no primeiro ano eram de 4 e no ano de 2010 passaram para 20 empresas de médio e grande porte a serem premiadas com o certificado da ALMT, conforme podemos verificar no gráfico 1 .

\section{Gráfico 1: Valores em mil reais, de investimentos das médias e grandes empresas} no seu ambiente indicadores sociais internos (ISI)

Fonte:dados da pesquisa, 2012

Em 2005 o investimento total no ISI das 4 médias e grandes empresas foi no valor de $\mathrm{R} \$ 17.921$ (dezessete milhões e novecentos e vinte e um mil reais) e no ano de 2010 esse valor foi considerável, devido ao aumento de empresas premiada pela ALMT, as 20 empresas investiram mais de $\mathrm{R} \$ 144.962$ (cento e quarenta e quatro milhões e novecentos e sessenta e dois mil) um aumento de $800 \%$ no valor do ISI e o aumento de $500 \%$ do número de empresa premiadas.

O gráfico 2 apresenta o percentual médio investido por ano, em relação a média de receitas líquidas das empresas. 
Gráfico 2: \% anual de ISI sobre (RL) das empresas analisadas - médias por ano

Fonte:dados da pesquisa, 2012

No ano de 2005, como vimos no gráfico 2, o investimento médio foi de 2,66\% da RL das 4 empresas premiadas. Houve uma queda de $1,78 \%$ passando de 2,66\% para $0,88 \%$, neste percentual no ano de 2006 a qual foram 9 empresas premiadas. No ano de 2007 houve um crescimento de $0,85 \%$ passando esse percentual de $0,88 \%$ para $1,73 \%$ e foram um total de 12 empresas premiadas. Nos anos de 2008 e 2009 apesar de serem números de empresas diferentes o percentual médio de investimentos foi o mesmo de $1,48 \%$, sendo que queda de 2007 para 2008 foi de $0,25 \%$ e se manteve no ano de 2009. No ano de 2010 o investimento teve um leve crescimento de $0,06 \%$ passando de $1,48 \%$ para $1,54 \%$.

O gráfico 3 mostra as médias dos 6 anos de investimentos das médias de grandes empresas em cada subitem do ISI.

\section{Gráfico 3: média de investimentos dos 6 anos por item do ISI}

Fonte: dados da pesquisa, 2012

Podemos perceber nitidamente, no gráfico 3, que os maiores subitens que receberam investimentos foram os de alimentação e outros (seguros (parcela paga pela empresa), empréstimo (só o custo), gastos com atividades recreativas, transportes, moradia e outros benefícios oferecidos aos empregados podem ser aqui enumerados). Sendo a "alimentação" o ISI que mais recebe investimento com um percentual de $26 \%$, seguido do ISI "outros", que recebe $24,57 \%$. O terceiro ISI a receber mais investimentos vem a ser o de "participação nos lucros e resultados", com 21,48\%. Em o quarto lugar o ISI "saúde" com 16,98\% os demais indicadores somados da um total de $10,97 \%$.

O gráfico 4 mostra o evolução dos indicadores por percentual da média da receita líquida ano a ano. Sendo que a soma dos ISI's Creches ou Auxílio-creche, Previdência Privada e Educação e Cultura não alcançaram, ao total de 6 períodos, o percentual de $11 \%$.

\section{Gráfico 4: a evolução do percentual (\%) sobre a RL}


*outros seguros (parcela paga pela empresa), empréstimo (só o custo), gastos com atividades recreativas, transportes, moradia e outros benefícios oferecidos os empregados podem ser aqui enumerados).

No ano de 2005 as 4 empresas premiadas investiram 31,77\% no ISI "saúde" No ano de 2006 houve mudanças nas prioridades das empresas. Com um total de 9 empresas, o investimento com maior percentual médio foi o da "alimentação" com 29,60\%, houve desta forma uma distribuição maior dos investimentos em outros segmentos. Em 2007 e 2008 o ISI de maior investimento foi “outros". Nos anos de 2009 e 2010 já são 20 empresas premiadas por ano, os investimentos principais voltaram para "alimentação".

Destes valores investidos, o gráfico 5 demonstra as 20 empresas premiadas e seu percentual de participação. As empresas Açofer, Data Med, H. Print, Maxvinil, Motos MT, Refrigerantes Marajá, Saúde Bucal, Unimed Vale do Sepotuba, e Vitória Régia representam menos de $1 \%$ do total dos investimentos.

\section{Gráfico 5: empresas em relação do total do ISI. (2010)}

Fonte: dados da pesquisa, 2012

Em 2010 o investimento total das M.G.E. foi de mais $\mathrm{R} \$ 144.962$ (cento e quarenta e quatro milhões e novecentos e sessenta e dois mil) no ISI. Como mostra o gráfico 5, as 20 empresas premiadas e seu percentual de participação. As empresas que mais investiram neste ano no ISI foram as do Grupo André Maggi, Centrais Elétricas, Usinas Itamarati e Supermercado Modelo.

\section{CONCLUSÃO}

Ser reconhecida como empresa socialmente responsável é a intenção de todas. No Mato Grosso a ALMT juntamente com a Comissão Mista de Responsabilidade Social da ALMT, premiam as empresas. Somente as empresas que apresentarem seu BS devidamente assinado pelo contador e a entrega da declaração assegurando a não utilização de mão de obra infantil, de trabalho análogo a escravidão, exploração sexual infantil e corrupção, compõe a concepção de responsabilidade social para que possa ser premiada com o certificado.

De acordo com Tinoco (2001), o Balanço Social é instrumento de gestão e informação que tem por objetivo mostrar, da forma mais transparente, informações econômicas e, principalmente sociais, relativas ao desempenho das entidades, para todos os seus usuários, inclusive seus funcionários. 
O procedimento adotado foi de coleta de dados documental, extraído do sítio da ALMT os BS das médias e grandes empresas que possuem o certificado do selo de responsabilidade social. Foram feitos a soma dos investimentos anuais dos indicadores sociais de ambiente interno destas empresas, o quanto as empresas, investiram por ano, em seu ambiente interno, como saúde, segurança e medicina do trabalho, capacitação e desenvolvimento profissional, creches ou auxílio-creche, previdência, educação e cultura, participação nos lucros e resultados e outros, por critério se percentual proporcional as receitas, como está descrito no modelo IBASE.

A questão problema foi respondida. Pois no ano de 2005 a média de \% sobre a RL foi de $2,66 \%$ e no ano de 2010, com o aumento da quantidade de empresas, caiu o percentual para $1,54 \%$ uma queda de $1,12 \%$. Podemos dizer que as empresas estão investindo menos com base nos valores dos investimentos em relação a RL das empresas. Dessa forma o objetivo geral da pesquisa foi alcançado.

Em 2010 as médias e grandes empresas que mais investiram em ISI foram as do Grupo André Maggi, localizada em Rondonópolis, com um percentual de 25,76\% em relação ao total da RL de 2010. A empresa Centrais Elétricas, localizada em Cuiabá, com 25,53\%. Usinas Itamarati, localizada no município Nova Olímpia, com 17,77\% e o Supermercado Modelo, localizada em Cuiabá com um percentual de 6,07\%.

O primeiro e o segundo objetivo foram alcançados, porém o terceiro não foi possível devido ao curto tempo que restou para concluí-lo. Foi focado nas pesquisas e busca de dados no sitio da ALMT, o qual foi encontrado dificuldades para a obtenção das informações necessárias para compor o banco de dados, devido alguns link's disponíveis estarem corrompido, necessitando assim o contanto com os responsáveis pela publicação via correio eletrônico, e para tanto o aguardo da restauração dos mesmos. Assim como não sendo possível o contato direto com as 26 empresas certificadas, via telefone, pois por motivo do horário comercial, a autora do artigo estava em seu trabalho e não seria ético usar o horário e nem o telefone para uso pessoal. Nem mesmo por correio eletrônico, para o questionamento sobre as razões que levaram as mesmas a publicarem Balanço Social (BS) e a se inscreverem no concurso de premiação. Sendo assim fica a sugestão para uma próxima pesquisa.

Conclui desta forma que, apesar de que houve aumento em valores dos investimentos no ambiente interno, em 2005 que eram mais de $\mathrm{R} \$ 17$ milhões para, $\mathrm{R} \$ 144$ milhões em 2010. Houve o aumento de 4 médias e grandes empresas no ano de 2005 para 20 empresas no de 2010 premiadas com o certificado. Porém o estudo mostra que a média dos investimentos 
por ano, em relação ao \% sobre a RL reduziram. De forma que em 2005 a média do \% sobre a RL foi de 2,66\%, no ano de 2010 caiu para 1,54\%. A conclusão dos resultados mostra que o ISI que mais recebeu investimentos das M.G.E.'s foi o de "alimentação". Afirma Baggenstoss que esse benefício esta previsto em lei e conta com um programa federal (PAT - programa de alimentação do trabalhador) que incentiva tal benefício com dedução de até $4 \%$ no imposto de renda devido das empresas que desejarem participar. O ISI que menos recebeu investimento foi de "creche ou auxílio creche". Esse benefício é obrigatório, consta na Consolidação das Leis Trabalhistas (CLT), criada pelo Decreto-Lei Federal n ${ }^{\circ} 5.452 / 43$. Os estabelecimentos em que trabalharem pelos menos 30 mulheres com mais de 16 anos de idade deverão manter uma creche ou oferecer o auxílio para elas.

\section{REFERÊNCIAS}

ASHLEY, Patrícia. A. "A mudança histórica do conceito de responsabilidade social empresarial". In: Paulo: Saraiva, 2005. p. 44-65. (coord.), Ética e responsabilidade social nos negócios. 2a ed. São

COSTA, Tânia Maria Zambelli de Almeida, 2000. Organização e Responsabilidade Social. Disponível em <http://www.pauloangelim.com.br/artigos3_4.html> Acesso em 30 de abril de 2012.

BAGGENTOSS, Salli e DONADONE, Julio. A Difusão Da Responsabilidade Social: Enfoque No Certificado De Responsabilidade Social De Mato Grosso. 2009. Disponível em <http://www.teoriaepesquisa.ufscar.br/index.php/tp/article/viewFile/212/159> Acesso em 10 de julho de 2012 .

FREIRE-MAIA, Newton. A ciência por dentro. Petrópolis: Vozes, 1998

FREIRE, Fátima de Souza et al. Balanço Social Abrangente: ferramenta contábil eficaz para mensuração do papel social das empresas. Revista Brasileira de Contabilidade, CFC, Brasília: ano $\mathrm{XXX}^{\circ}$ 130, julho/agosto de 2001.

GIL, Antonio Carlos. Como Elaborar Projetos de Pesquisa. 4. ed. São Paulo - SP:Atlas, 2008.

KRAEMER, Maria Elisabeth Pereira. Responsabilidade Social - uma alavanca para sustentabilidade. 2004 Disponível em

$<$ http://www.gestaoambiental.com.br/articles.php?id=34> Acesso em 28 de fevereiro de 2012

KRAEMER, M. E. P. TINOCO, J. E. P. Contabilidade e gestão ambiental. São Paulo: Atlas, 2004. 
LISBOA NETO, Hidelfôncio. Organização das informações do balanço social em instituição financeira como instrumento de gestão de sua responsabilidade social. Dissertação de mestrado, Florianópolis, 2003,

MATO GROSSO, LEI N 7.687 DE 25 DE JUNHO DE 2002. Responsabilidade Social no Estado de Mato Grosso e dá outras providências.

Disponível em:〈http://www.balancosocial.org.br/media/lei7687MT.pdf> Acesso em 29 de fevereiro de 2012.

MATO GROSSO, ASSEMBLÉIA LEGISLATIVA: Responsabilidade Social do Estado de Mato Grosso Certificado de Responsabilidade Social Disponível em 〈http://www.al.mt.gov.br/TNX/ http://www.al.mt.gov.br/TNX/index2.php?sid=245>

Acesso em 29de fevereiro 2012

MATARAZZO, Dante Carmine. Análise Financeira de Balanços: uma abordagem Básica e

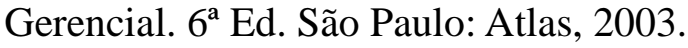

NOGUEIRA, Carlos. 2005. Disponível em $<$ http://www.vemconcursos.com/opiniao/index.phtml?page_id=1828> Acesso em 28 de fevereiro de 2012

PAIVA, Paulo Roberto de. Contabilidade Ambiental: Evidenciação dos gastos ambientais com transparência e focada na prevenção. São Paulo: Atlas, 2003.

RIBEIRO, Magno Alves, TORRES, Ariel Lopes e ROCHA, Margarida Alves. Manual para elaboração e apresentação de monografias: com noções introdutórias de metodologia. Tangará da Serra-MT: UNEMAT, 2005.

ROSSETTI, José Paschoal. Contabilidade Social. $4^{\text {a }}$ Ed. Revista e atual. São Paulo: Atlas, 1988

SANTOS, Carlos José Giudice dos, Tipos de pesquisa. Disponível em http://www.oficinadapesquisa.com.br/_OF.TIPOS_PESQUISA.PDF acesso em 30/04/2012

SIQUEIRA, José Ricardo Maia de, CARVALHO, Fernanda de M. Regulamentações brasileiras de balanço social. Rio de Janeiro: UFJ, 2005.

SILVA, César Augusto Tibúrcio, FREIRE Fátima de Souza (organizadores). Balanço Social: teoria e prática: inclui o novo modelo do IBASE São Paulo: Atlas, 2001.

SOUZA, Diocesar Costa de S. e PACHECO, Vicente. O Balanço Social atende aos objetivos a que se propõe? Paraná: UFPR,

TINOCO, João Eduardo Prudêncio. Balanço Social: uma abordagem de transparência e da Responsabilidade Pública das Organizações. São Paulo - SP: Atlas, 2001. 
Análise dos indicadores sociais internos de responsabilidade social das médias e grandes empresas certificadas pela Assembleia Legislativa de Mato Grosso

TINOCO, João Eduardo Prudêncio e KRAEMER, Maria Elisabeth Pereira. Contabilidade e Gestão Ambiental. São Paulo: Atlas, 2004.

TANABE,Cecília Yoko. Responsabilidade social interna (RSI). Disponível em $<$ http://www.nsk.com.br/4 2 rsi.asp > Acesso em 30 de abril de 2012 